\title{
scripted
}

Volume 13, Issue 2, August 2016

\section{El derecho penal y la pornografía infantil en el derecho comparado a nivel internacional, de Argentina, Estados Unidos y Europa}

\author{
Fernando J. Barrio ${ }^{1}$ and Maria Cecilia Sarricouet ${ }^{2}$
}

\begin{abstract}
The present article analyses the current situation of child pornography law at the international level and in three jurisdictions with different legal traditions, as well different developments in criminal law and criminal policy. It shows the problems associated with protecting children's sexual integrity from the perils represented by the use of new technology by sexual predators, while ensuring the free flow of information and ideas guaranteed by an array of rights such as freedom of expression and protection of privacy. It focuses on the legislative activity at the international level through the enactment of different conventions, the application of them by national authorities, the development of domestic legislation in the selected jurisdictions, and the response that courts have given to those developments. The article concludes with an in-depth analysis of the situation in Argentina and proposes a modification to the Criminal Code of Argentina.
\end{abstract}

\section{Resumen}

El presente artículo analiza la situación actual del derecho referido a la pornografía infantil a nivel internacional y en tres jurisdicciones con diferentes tradiciones legales y también diferentes avances en el derecho penal y política criminal. Muestra los problemas asociados con la protección de la integridad sexual de los niños de los peligros representados por el uso de las nuevas tecnologías por los depredadores sexuales, al tiempo que asegurar garantiza el libre flujo de información e ideas garantizados por una serie de derechos como la libertad de expresión y la protección de la privacidad. Se centra en la actividad legislativa a nivel internacional a través de diferentes tratados, su implementación por las autoridades nacionales, el desarrollo

\footnotetext{
${ }^{1}$ Professor of Law and Technology, Universidad Nacional de Rio Negro, Argentina.

${ }^{2}$ Assistant Professor of Law, Universidad Nacional de Rio Negro, Argentina.
} 
legal en general en las jurisdicciones. Se termina el análisis en profundidad de la situación de Argentina y proponer una modificación del Código Penal argentino.

DOI: $10.2966 /$ scrip.130216.171

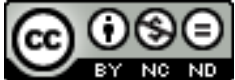

(C) Fernando J. Barrio and Maria Cecilia Sarricouet 2016. This work is licensed under a Creative Commons Licence. Please click on the link to read the terms and conditions.
} 


\section{Introducción}

El presente trabajo es el fruto del proyecto de investigación El Derecho Penal y la Protección de Menores en Internet, que fuera seleccionado en la Primer Convocatoria de Investigaciones Jurídicas de INFOJUS, del Ministerio de Justicia y Derechos Humanos de Argentina. Este proyecto tiene como director y co-directora a los autores de este artículo, pero es llevado adelante por un equipo formado por Marina Awe, Mercedes Barcos, Alfredo Bozzetti, Ana Lambrecht y Gonzalo Loriente, y tiene como objetivo analizar la adecuación del derecho penal argentino para la regulación legal ${ }^{1}$ de conductas llevadas a cabo a través de medios telemáticos que dañen real o potencialmente a menores de edad que las enfrentan como sujetos pasivos de las mismas. En este caso, debido a los requisitos de espacio incluidos en las condiciones del proyecto mencionado, la actividad se centra en el estudio de las cuestiones atinentes a la pornografía infantil, pero es necesario hacer notar que el proyecto también incluye las conductas las conocidas como cybergrooming y cyberbulling, y el uso de imágenes de menores, su privacidad y la protección de datos personales de los mismos, las cuales serán expuestas en una publicación mayor que incluya la totalidad del proyecto.

El análisis propuesto implica un necesario replanteo de algunas cuestiones básicas del derecho penal, su función y la protección de los menores de edad, siendo lo tecnológico no el factor determinante sino sólo el medio que, por su inmediatez y alcance, permite una observación más directa del impacto de ciertas conductas y su necesidad y o posibilidad de regulación, todo esto dentro de un paradigma filosófico que niega la posibilidad de un derecho que como actividad y como ciencia es neutro de valor, purificado y autorreferencial, reconociendo la necesidad de estudios sociolegales donde la validez, pertinencia y justificación de las normas estén signadas por razones y necesidades de la sociedad y las personas.

En ese contexto, es necesario recordar que lo tecnológico ha estado ligado al crecimiento económico y al desarrollo social desde que el ser humano se empezó a diferenciar de otros primates superiores, ${ }^{2}$ pero es indudable que en nuestro tiempo la tecnología ha llegado a ocupar un papel preponderante dentro de la forma de vida de las personas y de los factores de producción, especialmente las tecnologías de la información y las comunicaciones, dando lugar a la llamada Sociedad de la Información. ${ }^{3}$ Es así que se puede afirmar que sería difícil entrever una situación de desarrollo económico y social auto sostenido, con estructuras políticas y sociales estables y equitativas, en una sociedad sin acceso a las nuevas tecnologías y o con empresas que prescindan de ellas.

\footnotetext{
${ }^{1}$ Todo esto entendiendo que el derecho es una de las formas de regulación de conducta humana, siguiendo a Lessig en cuanto a que el mercado, las normas sociales y la arquitectura son los otros tres medios para regular lo que hace el hombre. L Lessig, Code and other Laws of Cyberspace (New York: Basic Books, 1999).

${ }^{2}$ Una de las posibles formas de definir el paso de primate a humano es el uso o no de herramientas o, siguiendo con nuestro vocabulario, tecnología. Ver P Ghosh, "First human' discovered in Ethiopia” (2015) disponible en http://www.bbc.co.uk/news/science-environment-31718336 (visitado 20 Sept $15)$.

${ }^{3}$ Para una discusión sobre el significado y alcance de la Sociedad de la Información, ver F Webster, Theories of the Information Society (Abingdon: Routledge, 2002).
} 
Las comunicaciones basadas en uso intensivo de tecnología, hoy de alcance global, son parte tanto de la causa como de las consecuencias del proceso de globalización, proceso que, se puede argumentar, no es reciente y data de la institución de las Compañías de Indias por parte del Imperio Británico, pero es innegable que los desarrollos tecnológicos del siglo XX sumados a la homogenización de los procesos productivos y empresariales, y los cambios culturales de principios del siglo XXI han contribuido a la creación de un mundo más globalizado e interdependiente que presenta tanto oportunidades como desafíos para las personas, las empresas y los gobiernos, sin dejar de lado las cuestiones atinentes al nivel de desarrollo relativo de un país al inicio del proceso, la posición en el mercado de una empresa y el nivel educativo y socio-económico de un individuo, distintas facetas de la llamada brecha digital. ${ }^{4}$ No obstante esto último, es en los países llamados en vías de desarrollo en donde se observa la mayor tasa de crecimiento del número de personas conectadas a alguna forma de tecnología de información y o comunicación de las que conforman el ciberespacio. ${ }^{5}$ Tal incremento en el uso de las tecnologías de información y comunicaciones han traído aparejados cambios sustanciales en la forma que las personas estudian, trabajan, interactúan entre sí y se divierten y han conllevado la aparición de una multiplicidad de nuevas oportunidades para los individuos y las empresas, así como una variedad de desafíos que la sociedad y el derecho debe enfrentar.

Los beneficios resultantes de la llamada edad de la información son múltiples y se encuentran extensamente documentados y analizados en la literatura, siendo cualquier selección dentro de un universo tan vasto, necesariamente parcial y hasta caprichosa. Sólo a modo de ejemplo, y haciendo énfasis en los aspectos sociológicos, económicos y legales del mencionado análisis, se pueden citar los trabajos de Manuel Castells, ${ }^{6}$ "La Internet en la vida diaria" de Wellman y Haythornthwaite," "Entendiendo la Economía Digital" de Brynjolfsson y $\mathrm{Kahin}^{8}$ y los informes anuales sobre la economía de la información de la Conferencia de Naciones Unidas sobre Comercio y Desarrollo (en adelante UNCTAD de acuerdo a su sigla en inglés ${ }^{9}$ ). Estos y otro gran grupo de autores hacer referencia a los cambios revolucionarios resultantes del uso extendido e intensivo de las tecnologías de la información y la comunicación, como

\footnotetext{
${ }^{4}$ R Vega-Almeida, "Brecha digital: un problema multidimensional de la sociedad emergente" (2007) 2 Inclusão Social 96-108.

${ }^{5}$ De acuerdo a las estadísticas proporcionadas por la Unión Internacional de Telecomunicaciones (de aquí en más UIT) la cantidad de personas en el mundo que usan Internet pasó del 11,65\% en al año 2001 al 39,77\% en el año 2011 y el uso de teléfonos celulares a nivel global se incrementó de un $16,40 \%$ en el año 2000 a un 91,51\% de la población en el año 2010.

${ }^{6}$ Especialmente su trilogía, La Sociedad de la Información (México: Siglo Veintiuno Editores, 1999) y la más nueva La Galaxia Internet (Barcelona: Plaza y Janés, 2001).

7 Traducción propia del título: The Internet in Everyday Life (Malden, MA: Blackwell Publishers, 2002).

${ }^{8}$ Traducción propia del título: Understanding the Digital Economy (Cambridge, MA: MIT Press, 2000).

9 El del año 2015 puede ser consultado en: "INFORME SOBRE LA ECONOMÍA DE LA INFORMACIÓN 2015" (2015) disponible en http://unctad.org/es/PublicationsLibrary/ier2015_es.pdf (visitado 26 Jul 16).
} 
los son los avances en comercio electrónico, el gobierno electrónico, ${ }^{10}$ el teletrabajo, ${ }^{11}$ la telemedicina, la cercanía desde el punto de vista comunicacional de lugares lejanos, el acceso al conocimiento a escala global y la expansión de las ideas de libertad, democracia e inclusión resultantes en cambios políticos en área donde regímenes autoritarios parecían lejos de perder su poder. ${ }^{12}$

De la misma manera que los cambios socio-culturales motivados por la revolución digital han significado avances en la calidad de vida de la personas y han posibilitado un mayor acceso al conocimiento y dispersión de poder tanto a nivel local como global, el uso de tecnologías de información y comunicaciones también han significado la aparición de problemas nóveles, la exacerbación de algunos existentes y el desarrollo y potenciamiento de conductas nocivas a nivel individual y comunitario. En su Comunicación del 16 de octubre de 1996 sobre Contenido Ilegal y Dañino en Internet, la Comisión Europea señalaba que

[1]a gran mayoría de contenido en Internet es tiene como objetivo información para uso de empresas o privado totalmente legítimo (y muchas veces altamente productivo). Sin embargo, como cualquier otra tecnología de la comunicación, particularmente en las etapas iniciales de su desarrollo, Internet acarrea una cantidad de contenido potencialmente dañino o ilegal o puede ser mal usada como vehículo para actividades criminales. ${ }^{13}$

Además de las ya mencionadas cuestiones de la brecha digital y la posibilidad del uso de las citadas tecnologías para lograr una mayor concentración del poder, la información y la riqueza, ${ }^{14}$ la evolución de las TICs han resultado en un marcado incremento en ciertos tipos de delitos y la aparición de nuevas conductas que afectan bienes jurídicos determinados, estén estas tipificadas o no. Más aún, las TICs controlan servicios esenciales tales como el suministro de agua y electricidad y el control de tráfico, los ascensores, el aire acondicionado y los sistemas telefónicos, con lo cual el potencial de daño aumenta en forma substantiva.

\footnotetext{
${ }^{10}$ F Barrio y A Bozzetti, "From Justice that Bites to Justice through Bites: Toward a More Transparent and Efficient Judicial System in the Rio Negro Province of Argentina", en S Edwards y D Santos (compiladores) Revolutionizing the Interaction between State and Citizens through Digital Communications (Hershey: IGI Global, 2015).

11 M Pino Estrada, "El teletrabajo en el derecho brasileño" disponible en http://www.alfaredi.org/sites/default/files/articles/files/pino.pdf (visitado $26 \mathrm{Jul} \mathrm{16).}$

${ }^{12}$ Para una reseña de los eventos de la llamada Primavera Arabe, ver: "Arab spring: an interactive timeline of Middle East protests" (2012) disponible en http://www.guardian.co.uk/world/interactive/2011/mar/22/middle-east-protest-interactive-timeline (visitado 26 Jul 16).

${ }^{13}$ COM (1996) 487.

${ }^{14}$ La discusión excede ampliamente el objetivo de este trabajo, pero uno de los resultados paradójicos del proceso de digitalización de la información y la economía ha sido que mientras este proceso permitiría un mayor acceso a la información, la tendencia a la propietización de la información y a la expansión de los sistemas globales de protección de la propiedad intelectual ha significado un menor acceso legal a la misma, ver, por ejemplo: F Barrio, "La 'propietización' de la información y el derecho a recibir conocimiento" (2015) 10 Revista Derecho Privado 3-20.
} 
El fraude a través de sistemas de información, la producción y distribución de pornografía infantil real y virtual y los ataques a la integridad de los servicios informáticos son algunos de los ejemplos de delitos relacionados con la informática que se cometen a gran escala todos los días. ${ }^{15}$ Los daños financieros causados por el ciberdelito son considerables e INFOSEC calcula que el costo global anual de tal forma delictual se sitúa entre 300.000 y 1.000 .000 de millones de dólares estadounidenses. ${ }^{16}$ Sin embargo, se puede argumentar que, más allá de las cuestiones financieras afectadas por estos crímenes, los delitos de daño o peligro a personas son los que deben ocupar la mayor atención de quienes tienen a su cargo el diseño e implementación de las políticas penales y, dentro eso delitos y las actividades nocivas llevadas a cabo mediante el uso de TICs, los que causan mayor preocupación son los que incluyen a niños como víctimas. ${ }^{17}$

Los delitos y las actividades llevados a cabo a través o mediante el uso de TICs que afectan, aunque no todos en forma exclusiva, a niños incluyen los ya nombrados pornografía infantil, ciberbullying, violación a sus derechos de imagen e intimidad, difusión de datos personales, el acoso sexual y el llamado cibergrooming.

\section{La pornografía infantil en Internet y su regulación comparada}

La definición de pornografía no es unívoca y cambia con la jurisdicción, pero en líneas generales se entiende como aquellos materiales visuales o táctiles que representan actos sexuales con el fin de provocar la excitación sexual del receptor. La pornografía no se limita a una sola disciplina y puede manifestarse en el cine, la fotografía, historietas, literatura, pinturas, esculturas y, sobre todo, Internet, pero en estos materiales también se encuentran aquellos de pornografía que incluye a menores de edad, o pornografía infantil.

Internet ha permitido un aumento dramático a nivel global en la pornografía infantil, ${ }^{18}$ tradicionalmente un comportamiento moralmente desviado y tabú llevado a cabo por pederastas o pedófilos y que deja a las víctimas con daño emocional y físico de toda la vida, siendo la cuestión del daño físico y psicológico sufrido por la víctima menor de edad fundamental para el análisis propuesto en este trabajo.

Mientras hay pocos datos sobre el efecto del uso de niños para la producción de pornografía, los daños causados por abuso sexual en menores están muy bien documentados, ${ }^{19}$ y se puede deducir que siendo la pornografía infantil una forma de

15 La organización Hacker Watch refiere más de 500.000 incidentes diarios de ataques informáticos:"Event Tracking” (2013) disponible en http://www.hackerwatch.org/ (visitado 26 Jul 16).

16 INFOSEC, "2013 - The Impact of Cybercrime" (2013) disponible en http://resources.infosecinstitute.com/2013-impact-cybercrime/ (visitado 26 Jul 16).

17 Si bien en términos generales se seguirá la definición de" niño" dada por el artículo 1 de la Convención de las Naciones Unidas sobre los Derechos del Niño, esta será una de las cuestiones a tratar en el artículo, dependiendo la edad de la conducta estudiada.

${ }^{18}$ Tal como lo expresa INTERPOL en su página dedicada a Crímenes contra niños: "Crimes against children" (2016) disponible en http://www.interpol.int/Crime-areas/Crimes-against-children/Crimesagainst-children (visitado 26 Jul 16).

19 J Briere y D Elliot, "Immediate and Long-Term Impacts of Child Sexual Abuse" (1994) 4 The Future of Children 54-69. 
registro del abuso sexual a un menor, sus víctimas experimentan las mismas consecuencias físicas y emocionales, sumadas al daño producido por la pornografía en sí misma. Víctimas de abuso sexual infantil sufren de angustia durante el período de explotación sexual, en el momento de la denuncia y en la etapa post-traumática. Además de los daños físicos sufridos, tienen instancias de depresión, aislamiento, ira y otros trastornos psicológicos. ${ }^{20}$

A los efectos de analizar en forma adecuada y en forma comparativa la respuesta que el derecho argentino ha dado a esta problemática, es menester examinar primero las convenciones y tratados internacionales que tratan sobre el tema, así como las políticas y regulaciones de las jurisdicciones con mayor influencia a nivel mundial en materia de política de Internet, como son los Estados Unidos y la Unión Europea. ${ }^{21}$

\subsection{La regulacióninternacional de la pornografía infantil}

Se puede argumentar que la pornografía infantil es un problema multi-jurisdiccional y que sólo un enfoque global mediante leyes uniformes puede tener impacto sobre esta problemática, a fin de evitar que las diferentes posturas de las legislaciones nacionales sobre pornografía infantil permita que los perpetradores concentren sus esfuerzos en jurisdicciones con regulaciones inexistentes o más laxas.

Los tres principales instrumentos jurídicos internacionales que se ocupan de la pornografía infantil son el Protocolo facultativo sobre la venta de niños, la prostitución infantil y la utilización de niños en la pornografía, ${ }^{22}$ el Convenio sobre Ciberdelincuencia del Consejo de Europa ${ }^{23}$ y el Convenio del Consejo de Europa para la protección de los niños contra la explotación y el abuso sexual. ${ }^{24}$ Estos tratados contienen definiciones específicas de delitos, así como disposiciones que exigen castigo para las conductas criminalizadas.

\footnotetext{
${ }^{20}$ E Klain, H Davies y M Hicks, “Child Pornography: The Criminal-Justice-System Response” ( 2001) disponible en http://www.popcenter.org/problems/child_pornography/PDFs/Klain_etal_2001.pdf (visitado 26 Jul 16).

${ }^{21}$ Estando claro que la Unión Europea no es un país, a los efectos de este estudio importa que tiene la capacidad para dictar leyes obligatorias para sus miembros, directamente aplicables por los sistemas judiciales de los mismos y con efecto directo sobre los ciudadanos, tal cual lo establecido por la Corte Europea de Justicia (en adelante CEJ) en el caso Flaminio Costa v ENEL, Case 6/64, [1964] ECR 585 (en adelante Costa v ENEL), el Tratado sobre el Funcionamiento de la Unión Europea en su artículo 288 y nuevamente la CEJ en el caso Van Gend en Loos v. Nederlandse Administratie der Belastingen, Case 26/62, [1963] ECR 1 (en adelante Van Gend en Loos).

22 "Protocolo facultativo de la Convención sobre los Derechos del Niño relativo a la venta de niños, la prostitución infantil y la utilización de niños en la pornografía" (2002) disponible en http://www.ohchr.org/SP/ProfessionalInterest/Pages/OPSCCRC.aspx (visitado 26 Jul 16).

23 "Convention sur la cybercriminalité" (2004) disponible en http://conventions.coe.int/Treaty/en/Treaties/Html/185-SPA.htm (visitado 26 Jul 16).

24 "Convention du Conseil de l'Europe sur la protection des enfants contre l'exploitation et les abus sexuels" (2010) disponible en http://www.conventions.coe.int/Treaty/EN/treaties/Html/201.htm (visitado 26 Jul 16).
} 
La Convención sobre los Derechos del Niño ${ }^{25}$ (en adelante la CDN), tiene por objeto garantizar una amplia gama de derechos humanos para los niños, incluyendo derechos civiles, culturales, económicos, políticos y sociales, pero también incluye disposiciones relativas a la explotación sexual infantil. El artículo 34 de esta Convención establece claramente que los Estados partes deben tomar medidas preventivas para hacer frente a la explotación sexual de y abuso sexuales de niños, llevando adelante las acciones de alcance nacional, bilateral y multilateral para prevenir la explotación de menores en espectáculos o materiales pornográficos.

El Protocolo facultativo sobre la venta de niños, la prostitución infantil y la utilización de niños en la pornografía entró en vigor el 18 de enero de 2002 y define a la pornografía como "toda representación, por cualquier medio, de un niño dedicado a actividades sexuales explícitas, reales o simuladas, o toda representación de las partes genitales de un niño con fines primordialmente sexuales", ${ }^{26}$ para luego exigir en su artículo 3 inciso $1 \mathrm{c}$ ) que los Estados Partes tipifiquen como delito la pornografía infantil, ya sea cometida en el país o en el extranjero y de forma individual $u$ organizada, incluyendo la simple posesión, con un agregado, entre comas en la versión en español ${ }^{27}$, que introduce la cuestión de la intención de una forma confusa, aunque hace suponer que se refiere a la posesión con intención de llevar a adelante las conductas descriptas previamente en el mismo artículo e inciso. También hace un llamado al establecimiento de responsabilidad, civil, administrativa o penal, para las personas jurídicas en el entendimiento que un enfoque integral sobre la cuestión requiere la participación de la industria. A tono con las razones de esta sección del trabajo, el artículo 10 inciso 1 se refiere a que, atendiendo al hecho de que la pornografía se distribuye fácilmente a través de las fronteras por vía telemática, la cooperación internacional se presenta como perentoria.

Siguiendo con esa línea y viendo la relativa facilidad con la que las tecnologías de la información y las comunicaciones permiten a los delincuentes accionar en diferentes jurisdicciones de aquellas de las víctimas de sus delitos, el Consejo de Europa ${ }^{28}$ estableció su Convenio sobre la Ciberdelincuencia (también conocido como el Convenio de Ciberdelincuencia y aquí usado en forma indistinta, también en adelante el Convenio) con la esperanza de implementar un enfoque cooperativo y uniforme para el enjuiciamiento de los delitos cibernéticos. El Convenio de Ciberdelincuencia

25 "Convención sobre los Derechos del Niño" (1989) disponible en http://www.ohchr.org/SP/ProfessionalInterest/Pages/CRC.aspx (visitado 26 Jul 16).

${ }^{26}$ Artículo 2, inciso C.

27 En la versión en inglés la frase está sin comas, con lo cual dice claramente "poseer para los propósitos de arriba", aunque todavía abierto a la interpretación de si "arriba" se refiere a las conductas anteriormente citadas en el mismo artículo o más arriba en el texto.

${ }^{28}$ Este consejo no debe ser confundido con el Consejo la Unión Europea. Como explica el Ministerio de Relaciones Exteriores de España, "El Consejo de Europa es "una organización internacional que tiene como objetivo principal la defensa y protección de la democracia, el Estado de Derecho y los derechos humanos, en particular los civiles y políticos. Se trata de la institución de este tipo más antigua de nuestro continente y engloba a la totalidad de las naciones europeas con la sola excepción de Bielorrusia. Tiene su sede en la ciudad francesa de Estrasburgo y su órgano más activo es el Tribunal Europeo de Derechos Humanos." Más información en: "Consejo de Europa" disponible en http://www.exteriores.gob.es/PORTAL/ES/POLITICAEXTERIORCOOPERACION/CONSEJODEEU ROPA/Paginas/Inicio.aspx (visitado 26 Jul 16). 
está abierto a la firma por los Estados miembros de Europa y los Estados no miembros que han participado en su elaboración, y a la adhesión de otros Estados no miembros.

Dentro del Título 3, Delitos relacionados con el contenido, el artículo 9 del Convenio, en su inciso 1, establece la obligatoriedad de los Estados Partes de tipificar la producción de pornografía infantil para la distribución a través de un sistema informático, el ofrecer o poner a disposición pornografía infantil a través de un sistema informático, el distribuir o transmitir pornografía infantil a través de un sistema informático, el adquirir pornografía infantil a través de un sistema informático para uno mismo o para otra persona y el poseer pornografía infantil en un sistema informático o en un medio de almacenamiento de datos informáticos. Es importante aquí ver como la sola posesión esta efectivamente tipificada como delito.

El inciso 2 del mismo artículo define a la pornografía infantil como todo material pornográfico que represente de manera visual a un menor participando en una conducta sexualmente explícita, a una persona que parezca ser un menor de edad participando en una conducta sexualmente explícita, y o a imágenes realistas que representen a un menor de edad involucrados en una conducta sexualmente explícita.

En línea con la Convención de los Derechos del Niño, el artículo 9 inciso 3 del Convenio dice que el término menor debe incluir a todas las personas menores de 18 años de edad, aunque dando la posibilidad de que un Estado Parte establezca una edad menor, que no podrá ser inferior a los 16 años.

Los artículos 11, 12 y 13 se ocupan de la cuestiones de la tentativa y complicidad, la responsabilidad de las personas jurídicas y de las penas, respectivamente, finalizando la parte que nos interesa con el artículo 23 referido a la cooperación internacional.

El mismo Consejo de Europa estableció la Convención para la Protección de los Niños contra la Explotación Sexual y el Abuso Sexual, también conocida como la Convención de Lanzarote, un tratado internacional que se centra en garantizar el interés superior de los niños a través de la prevención del abuso y la explotación, la protección y asistencia a las víctimas, el castigo a los autores, y la promoción de la cooperación nacional e internacional. Esta Convención se abrió a la firma el 25 de octubre de 2007 y entró en vigor el 1 de julio 2010, estando abierta a la firma de los Estados miembros, los Estados no miembros que han participado en la elaboración de la Convención, la Comunidad Europea y la adhesión de otros Estados no miembros. ${ }^{29}$

Con respecto a la pornografía infantil la Convención de Lanzarote, en su artículo 20 inciso 1 exige a los Estados Partes tipificar como delito la producción de pornografía infantil, el ofrecimiento o puesta a disposición de pornografía infantil, la distribución o transmisión de pornografía infantil, el procurar pornografía infantil para uno mismo

\footnotetext{
${ }^{29}$ El listado de Estados que han firmado la Convención puede ser encontrado en: "Chart of signatures and ratifications of Treaty 201 Council of Europe Convention on the Protection of Children against Sexual Exploitation and Sexual Abuse" (2016) disponible en http://www.coe.int/en/web/conventions/full-list/-/conventions/treaty/201/signatures (visitado 26 Jul 16).
} 
o para otra persona, la posesión de pornografía infantil y el acceso, con conocimiento, a pornografía infantil a través de tecnologías de la información y de la comunicación.

La pornografía infantil es definida como "cualquier material que represente de manera visual a un niño en una conducta sexualmente explícita real o simulada o cualquier representación de los órganos sexuales de un niño con fines primordialmente sexuales" ${ }^{30}$ y se recomienda a los Estados Partes a adoptar legislación penalizando las actividades de reclutar o coaccionar a un niño para que se parte de actividades de pornografía infantil o con conocimiento asistir a representaciones de pornografía infantil. ${ }^{31}$

Al igual que el Convenio sobre la Ciberdelincuencia, la Convención de Lanzarote refiere a las cuestiones de tentativa y complicidad, responsabilidad de las personas jurídicas y cooperación internacional.

\subsection{La pornografía infantil en el derecho de los Estados Unidos de América}

La Corte Suprema de los Estados Unidos, ha establecido que los derechos protegidos por la Primera Enmienda a la Constitución de los Estados Unidos ${ }^{32}$ (en adelante Primera Enmienda) merecen un trato preferencial, lo cual los pone de hecho en una categoría superior de derechos. ${ }^{33}$ Ésta ha significado la protección de expresiones, actividades e imágenes fuertemente reguladas o prohibidas en otras jurisdicciones. ${ }^{34}$ Sin embargo, las imágenes obscenas no están protegidas por la Primera Enmienda, siendo una forma de definirlas justamente es falta de protección, tal lo explicado por el Juez de la Suprema Corte norteamericana Alito en su opinión disidente en United States $v$ Stevens 559 US 460 (2010) (en adelante United States v Stevens). ${ }^{35}$

Eso ha llevado a que resulte de suma importancia el definir lo que es y no es obsceno y la Corte Suprema norteamericana ha establecido el cómo decidirlo en el caso Miller $v$ California 413 US 15 (1973) (en adelante Miller v California o Miller), diciendo que un material es obsceno (a) si "una persona común, al aplicar los estándares comunitarios vigentes" concluiría que la obra, considerada en su totalidad, atrae a un interés lascivo, (b) si la obra representa o describe, de un modo manifiestamente ofensivo, una conducta sexual definida expresamente por la ley del estado aplicable; y (c) si la obra, en general, carece de un valor literario, artístico, político o científico serio. Esto deja la posibilidad de que la pornografía sea legal, protegida por la Primera Enmienda, dependiendo de los estándares de esa comunidad o planteándola

\footnotetext{
${ }^{30}$ Artículo 20, inciso 2.

${ }^{31}$ Artículo 21, inciso 1.

${ }^{32}$ La Primera Enmienda a la Constitución de los Estados Unidos prohíbe la creación de cualquier ley con respecto al establecimiento de una religión, o que impida la práctica libre de la misma, o que reduzca la libertad de expresión, o que vulnere la libertad de prensa, o que interfiera con el derecho de reunión pacífica o que prohíba peticionar al gobierno.

${ }^{33}$ Ver United States v Carolen Products 304 US 144 (1938) y Palko v Connectict 302 US 319 (1937).

${ }^{34}$ Contrastar las prohibiciones de imágenes o discurso apologético del nazismo en Europa con fallos de la Corte Suprema de los Estados Unidos como National Socialist Party of America v Village of Skokie 432 US 43 (1977) en el que se permitió una marcha nazi en un barrio judío.
}

${ }^{35}$ Opinión disidente de Alito, p. 13. 
como teniendo valor artístico. Sin embargo, tal como lo explicado en la referida disidencia del Juez Alito en United States v Stevens, la distribución de imágenes de pornografía infantil no está protegida por la Primera Enmienda, tal como lo decidió la Corte Suprema de los Estados Unidos en New York v. Ferber 458 U.S 747 (1982) (en adelante Ferber), así como la posesión de las mismas, siguiendo a Osborne v. Ohio 495 U.S 103 (1990), de la misma Corte Suprema.

La sección 2256 del Título 18 del Código de los Estados Unidos define pornografía infantil como cualquier representación visual de una conducta sexual explícita que involucre a un menor, categorizando a éste como a una persona con menos de 18 años de edad. ${ }^{36}$ Representación visual incluye fotografías, videos, imágenes generadas en forma digital o por computadoras indistinguibles de un menor real, e imágenes creadas, adaptadas o modificadas que parezcan representar a un menor real e identificable. Esto fue incorporado por la Child Pornography Prevention Act de 1996, ley para la prevención de la pornografía infantil, pero esta definición, todavía en el Código de los Estados Unidos, fue invalidada por la Suprema Corte de Justicia de los Estados Unidos, en Ashcroft v Free Speech Coalition 535 US 234 (2002), en donde decidió que las palabras "parezcan representar" eran demasiado vagas y dictó la inconstitucionalidad de ciertas partes de la ley que las agregó al mencionado código. De la misma manera y en el mismo caso, también declaró inconstitucional la inclusión de imágenes generadas por computadoras dentro del concepto de pornografía infantil, en tanto que la prohibición de distribución y tenencia de pornografía infantil estaba destinada a proteger a los niños-víctimas, que en este caso no existirían. ${ }^{37}$ Rollos de fotografía sin revelar, cintas de video sin revelar y datos guardados en forma electrónica que puedan ser convertidos en imágenes de pornografía infantil también son consideradas ilegales, no siendo necesario que el menor esté tomando parte en actividad sexual propiamente dicha, ya que una foto sexualmente sugestiva de un menor desnudo también puede ser considerada pornográfica, tal lo establecido en United States v Dost, 636 F. Supp. 828, (S.D. Cal. 1986). En todos los casos la representación de un menor de 18 años en conductas sexuales explícitas es ilegal, más allá de la edad de consentimiento sexual en un determinado estado, lo cual es importante la para discusión del caso argentino.

La ley federal norteamericana prohíbe la producción, distribución, recepción y posesión de imágenes de pornografía infantil utilizando o que afecten a cualquier medio o instalación de comercio interestatal o extranjero. ${ }^{38}$ Específicamente, la Sección 2251 establece que es ilegal persuadir, inducir, seducir o coaccionar a un menor de edad a participar en una conducta sexualmente explícita a los efectos de la producción de representaciones visuales de esa conducta. La ley federal admite los delitos en grado de tentativa y también penaliza a los partícipes del mismo. Una de las

\footnotetext{
3618 U.S.C., Chapter 110, Sexual Exploitation and Other Abuse of Children, $§ 2256$ - "Definitions for chapter", disponible en https://www.law.cornell.edu/uscode/text/18/2256 (visitado 26 Jul 16).

${ }^{37}$ Es importante señalar que en este caso la Corte Suprema de los Estados Unidos no legalizó la totalidad de la pornografía infantil virtual, en cuanto ésta todavía debía satisfacer los requerimientos establecidos en el mencionado caso Miller.

${ }^{38}$ Ver 18 U.S.C. $\S 2251$ - Sexual exploitation of children; 18 U.S.C. $\S 2252$ - Certain activities relating to material involving the sexual exploitation of minors; 18 U.S.C. $\S 2252 \mathrm{~A}$ Certain activities relating to material constituting or containing child pornography.
} 
cuestiones que más conflicto ha producido a nivel doctrinario es el monto de las penas, que en casos superan los 20 años de prisión de mínimo. ${ }^{39}$

La pornografía infantil atrae jurisdicción federal si el delito se lleva a cabo en el comercio interestatal o extranjero, como sería el uso del correo o empresas de transporte público para trasladar el material pornográfico. Además, la jurisdicción federal casi siempre se aplica cuando se utiliza la Internet para enviar o recibir pornografía infantil. Más aún, si la imagen de pornografía infantil en sí atravesó las fronteras estatales o internacionales, la ley federal puede estar implicada si los materiales, como el equipo utilizado para descargar la imagen o almacenar la imagen, se originaron o previamente atravesaron límites estatales o internacionales. La Sección 2260 del Título 18, Código de Estados Unidos (18 U.S.C. por sus siglas en inglés), prohíbe a cualquier persona fuera de los Estados Unidos producir a sabiendas, recibir, transportar, enviar, o distribuir pornografía infantil con la intención de importarla o transmitirla a los Estados Unidos.

Como se dijo anteriormente, cualquier violación de la ley federal de pornografía infantil es un delito grave y las penas son todas sustantivas. Por ejemplo, un condenado por primera de producir pornografía infantil en virtud de 18 U.S.C. $\S 2251$, se enfrentan a multas y a una pena de presión de entre 15 y 30 años. De acuerdo a la sección 2252 del 18 U.S.C., una persona condenada por primera vez por el transporte de pornografía infantil en el comercio interestatal o extranjero, se enfrenta a multas y un mínimo estatutario de 5 años a 20 años como máximo en prisión. Las penas ascienden hasta cadena perpetua en los casos de reincidencia o si el delito de pornografía infantil se produjo en situaciones agravadas, definidas como aquellas en donde las imágenes son violentas, sádico o masoquista, el menor fue abusado sexualmente, o el reo tiene condenas previas por la explotación sexual infantil.

La legislación antedicha no ha sido exenta de controversia, entendiéndose en los Estados Unidos que las leyes no son constitucionales porque amenazan el derecho protegido de la libertad de expresión, y que es supuestamente imposible de detectar adecuadamente el origen de una transmisión de Internet cuando el usuario usa técnicas activas de evasión. Lo conflictivo de esta cuestión es observado en la gran cantidad de trabajos académicos que analizan el tema desde una perspectiva que en nuestro país llamaríamos garantista, los cuales contrastan con el tratamiento de los medios de comunicación que llaman continuamente a aumentar las penas para los delitos de esta índole. ${ }^{40}$ La jurisprudencia de ese país no se ha mantenido al margen de la polémica.

La Suprema Corte de Justicia ha dictaminado en Reno v American Civil Liberties Union 521 US 844 (1997) (en adelante Reno v American Civil Liberties Union), que la Communications Decency Act es inconstitucional en cuanto no se puede prohibir la

\footnotetext{
${ }^{39}$ La cuestión de lo excesivo de la pena está tratado en forma muy gráfica en C Hessick, "The Limits of Child Pornography” (2014) 89 Indiana Law Journal 1437 disponible en: http://www.repository.law.indiana.edu/ilj/vol89/iss4/4 (visitado 26 Jul 16).

${ }^{40}$ Para un artículo de difusión que escapa de la tendencia, ver A Extein, "Capitol Punishment: The Troubling Consequences of Federal Child Pornography Laws" (2014) disponible en http://www.huffingtonpost.com/andrew-extein-msw/capitol-punishment-the-tr_b_4756400.html (visitado 26 Jul 16).
} 
transmisión de imágenes indecentes, las cuales estaban definidas siguiendo de cerca lo establecido en el mencionado caso Mille $v$ Calidornia, afirmando que no se puede reducir el material disponible para adultos a sólo lo que es adecuado para los niños. Más aún, cuando el Congreso de los Estados Unidos intentó limitar la distribución de material que era considerado obsceno mediante el establecimiento de filtros tecnológicos para dicho material en la Child Online Protection Act de 1998 (Ley de Protección de los Niños en línea), la Corte Suprema de ese país nuevamente la consideró inconstitucional en Ashcroft v. American Civil Liberties Union 535 US 564 (2002) (en adelante Reno v ACLU). Sin embargo, sólo un año más tarde en United States v American Library Association 539 US 194 (2003) (en adelante United States $v$ American Library Association), el supremo tribunal de Estados Unidos decidió que el instalar filtros para pornografía en las bibliotecas públicas, tal lo establecido por la Children's Internet Protection Act (Ley para la Protección de los Niños en Internet), si era constitucional y respetuoso de la Primera Enmienda.

El Congreso de los Estados Unidos, en respuesta a las decisiones judiciales y los análisis doctrinarios, aprobó en el año 2003 la ley PROTECT, acrónimo para Prosecutorial Remedies and Other Tools to end the Exploitation of Children Today (remedios y otras herramientas de la fiscalía para terminar la explotación de niños hoy), que, entre otras disposiciones, prevé la cadena perpetua obligatoria de los condenados por delitos sexuales contra un menor si éstos han tenido una condena previa de abuso contra un menor de edad, con algunas excepciones, autoriza las escuchas telefónicas y la vigilancia de otras comunicaciones en todos los casos relacionados con el abuso de menores, elimina los plazos de prescripción para los delitos de sustracción de menores o abuso infantil, prohíbe la libertad condicional personas acusadas de delitos que involucran a niños, prohíbe la pornografía infantil generada por computadora cuando la representación visual es una imagen de computadora o una imagen generada por ordenador de un menor participando en una conducta sexualmente explícita o es prácticamente indistinguible de ella, prohíbe dibujos, esculturas, e imágenes de dichos dibujos y esculturas que representan menores en acciones o situaciones que cumplen la prueba de Miller de ser obsceno, o se dedican a actos sexuales que se consideran igualmente obscenos.

Esa ley establece una pena máxima de 5 años por posesión de pornografía infantil y de 10 años para la distribución de la misma, y autoriza multas y / o penas de prisión de hasta 30 años para los ciudadanos estadounidenses o residentes que se involucran en conducta sexual ilícita en el extranjero. A los efectos de esta ley, la conducta sexual ilícita se define como el comercio sexual con o abuso sexual de menores de 18 años, o de cualquier sexo con cualquier persona menor de 16 años.

Se observa que la Ley PROTECT incluye prohibiciones de ilustraciones que muestran pornografía infantil, incluyendo pornografía infantil virtual, siendo que las disposiciones contra la pornografía infantil virtual de la Ley de Prevención de la Pornografía Infantil de 1996 habían declarado inconstitucionales en el ya mencionado Ashcroft v. Free Speech Coalition. Más aún, al reafirmar la constitucionalidad de la Ley en lo que respecta a la prohibición de ofrecer pornografía infantil o pornografía que se cree es infantil, en USA $v$ Williams 553 US 285 (2008) (en adelante USA $v$ Williams), la Corte Suprema de los Estados Unidos aclaró explícitamente que una oferta de proveer o requerir pornografía infantil virtual no estaba prohibida por la Ley. Un crimen era cometido sólo cuando el que hablaba creía o pretendía hacer creer a 
quien escuchaba, que el objeto de la transacción propuesta mostraba niños reales. ${ }^{41}$ Sin embargo, y en concordancia de tanto el test establecido en Miller como la protección de los derechos de la Primera Enmienda en Ashcroft v Free Speech Coalition, las imágenes de pronografía virtual infantil sí serían ilegales si son consideradas obscenas, como en el caso de United States $v$ Whorley, No. 06-4288, Fourth Circuit Court of Appeals (2008), en donde la Cámara de Apelaciones para el Cuarto Distrito encontró que la restricción a la pornografía infantil virtual obscena era constitucional y que no restringía a la pornografía no obscena del tipo permitido en el caso Ferber.

Hoy en día, la discusión parece estar centrada en la punibilidad de la posesión sin el necesario grado de intención, por ejemplo con imágenes grabadas automáticamente en el caché de la máquina, y, a su vez, si esto no implicaría una defensa automática para los casos que la posesión sea grabada en forma automática por la computadora del imputado. ${ }^{42}$

\subsection{El derecho de la Unión Europea y la pornografía infantil}

Hasta el año 2011, el principal documento legal que trataba la cuestión de la protección de los menores el abuso sexual y la explotación dentro de la Unión Europea fue la Decisión marco 2004/68 / JAI del Consejo sobre la lucha contra la explotación sexual de los niños y la pornografía infantil ${ }^{43}$ (en adelante la Decisión Marco), que en su artículo 1 define a niño como toda persona menor a 18 años y a la pornografía infantil como cualquier material pornográfico que visualmente representa o representa:

i) a un niño real practicando o participando en una conducta sexualmente explícita, incluida la exhibición lasciva de los genitales o de la zona púbica de un niño, o ii) a una persona real que parezca ser un niño practicando o participando en la conducta mencionada en el inciso o iii) imágenes realistas de un niño inexistente practicando o participando en la conducta mencionada en el inciso.

Además de que el punto 5 de los Considerandos de la Decisión Marco reza "[1]a pornografía infantil, forma especialmente grave de explotación sexual de los niños, se está desarrollando y extendiendo por medio de las nuevas tecnologías e Internet", la relación entre la pornografía infantil e Internet es reconocida desde el principio en el texto legal en cuestión, siendo que la definición que sigue en el mismo artículo es la de sistema informático. ${ }^{44}$

\footnotetext{
${ }^{41}$ USA $v$ Williams, $\mathrm{p} 13$.

${ }^{42}$ Ver, por ejemplo, G Marin, "Possession of Child Pornography: Should You be Convicted When the Computer Cache Does the Saving for You?" (2008) 60 Florida Law Review 1205 disponible en http://scholarship.law.ufl.edu/flr/vol60/iss5/6 (visitado 26 Jul 16).

43 “Lucha contra la explotación sexual de la infancia y la pornografía infantil" (2003) disponible en
http://eur-lex.europa.eu/legal-content/ES/TXT/?uri=uriserv:133138 (visitado 26 Jul 16).
}

${ }^{44} \mathrm{El}$ que es definido como “...cualquier dispositivo o conjunto de dispositivos interconectados o relacionados, uno o más de los cuales realice, de acuerdo con un programa, un tratamiento automático de datos." 
En cuanto a los tipos penales asociados a la pornografía infantil identificados en el texto legal europeo, se introducen la distribución, difusión, transmisión, oferta o puesta a disposición, adquisición y tenencia. Es importante señalar que, debido a que no se especifica a partir de qué condiciones se sanciona la producción de material, lo cual incluye en el tipo la conducta de producir sin vista a distribución, éste tiene un alcance amplio.

Por otro lado, la Decisión Marco dispone que los estados miembros tienen la libertad de decidir eximir de toda responsabilidad penal a un individuo en los casos que el material pornográfico retrata a una persona que parece ser una persona menor de edad pero no lo era al momento de producir el material, aunque la intención sea dar la impresión al consumidor del material que la persona en cuestión es un menor de edad. Un estado parte puede establecer que no es delito cuando un individuo posee material de pornografía infantil producido por él mismo, que retrata a personas menores reales $\mathrm{y}$ personas que parecen ser menores pero no lo son, cuando al momento de ser producido el material, la persona menor de edad tiene la edad legal de consentimiento para tener relaciones sexuales prevista en la legislación del país donde se produce el material, que ésta haya dado su consentimiento, y que el material esté destinado solamente al uso privado de la persona que lo produjo, siendo necesario que se den las tres condiciones. Aun así, cuando se dieran estas tres condiciones pero el mayor haya obtenido el consentimiento del menor mediante alguna forma de abuso de poder, tal consentimiento se considerará viciado y no válido.

En la misma línea, un país miembro de la Unión Europea puede no penalizar la posesión de material que reproduce imágenes realistas de personas menores de edad que no existen en los casos que la persona que posea el material lo haya producido, lo tenga únicamente para su uso privado, no exista ningún riesgo de que este material sea difundido, y ninguna persona menor de edad real o ninguna persona que parezca ser menor de edad pero que en realidad sea mayor de edad haya sido usada para producir el material.

En general se puede argumentar que la Decisión Marco no resultó ser un gran éxito en la lucha contra el abuso de menores y la pornografía y que esta falta de éxito estuvo relacionada con la no inclusión del abuso sexual como parte de la conducta punible, limitándola sólo a "conducta sexual explícita", así como el hecho de que la Decisión Marco, por su naturaleza jurídica dentro del sistema legal europeo, no tenía efecto directo, esto significa que lo dispuesto, si no se incorpora en su totalidad en la legislación de los estados partes, no puede invocarse directamente ante los tribunales nacionales.

Con la entrada en vigor del Tratado de Lisboa por el que se modifican el Tratado de la Unión Europea y el Tratado constitutivo de la Comunidad Europea ${ }^{45}$ (en adelante Tratado de Lisboa) se introdujeron algunos cambios en la esfera de los asuntos penales en la Unión Europea. Las decisiones marco han sido sustituidas por las directivas en virtud del artículo 82 y 83 del Tratado de Funcionamiento de la Unión

\footnotetext{
45 “Tratado de Lisboa" disponible en http://ec.europa.eu/archives/lisbon treaty/full text/index_es.htm (visitado 26 Jul 16).
} 
Europea (en adelante TFUE). El art 82 (1) establece que la cooperación judicial en materia penal en la Unión Europea debe basarse en el principio de reconocimiento mutuo de las sentencias y decisiones judiciales, lo cual lleva a la necesidad de armonización de las distintas leyes penales. El segundo párrafo del mismo artículo establece, además, que para facilitar la cooperación en materia penal, el Parlamento Europeo y el Consejo podrán establecer normas mínimas mediante Directivas, significando que las definiciones de delitos y los niveles de sanciones penales se encuentren bajo un mismo documento. En virtud del artículo 288 del TFUE, las directivas adoptadas son vinculantes y directamente aplicable en todos los Estados miembros, lo que implica que sus disposiciones estarán en vigor en la legislación nacional, incluso si no se ha aplicado a tiempo o de una manera correcta por los Estados miembros, a menos que lo establecido no sea claro e incondicional. ${ }^{46}$

Sin embargo, en caso de que un Estado miembro reconozca una amenaza para su sistema de justicia penal en el texto de un proyecto de directiva, puede frenar el proceso de sanción y proponer el proyecto al Consejo para su discusión adicional.

En 2011, el Parlamento Europeo y el Consejo adoptaron una nueva directiva para luchar e imponer mayores sanciones penales a quienes lleven adelante las conductas objeto de este trabajo, la Directiva 2011/92 relativa a la lucha contra los abusos sexuales y la explotación sexual de los menores y la pornografía infantil y por la que se sustituye la Decisión marco 2004/68/JAI del Consejo (en adelante la Directiva contra la explotación sexual de los menores, la Directiva 2011/92 o simplemente la Directiva), la cual en líneas generales establece penas más severas y un alcance más amplio de las conductas tipificadas como delitos, además de contemplar la inhabilitación para ciertos trabajos de los convictos.

A través de dicha Directiva 2011/92, la Unión Europea ha buscado cumplir con el artículo 24 de la Carta de los Derechos Fundamentales de la Unión Europea, ${ }^{47}$ haciendo hincapié en normas más estrictas en materia de derecho penal y procesal dentro de los Estados miembros que deberían proteger el interés superior de los niños, siendo a su vez eficaces, proporcionadas y disuasorias.

La Directiva contra la explotación sexual de los menores da una definición de pornografía infantil en línea con el Protocolo facultativo de la Convención sobre los Derechos del Niño relativo a la venta de niños, la prostitución infantil y la utilización

\footnotetext{
${ }^{46}$ De acuerdo al criterio establecido por la Corte Europea de Justicia en el ya nombrado caso de Van Gend en Loos.

${ }^{47}$ El artículo reza: Derechos del menor
}

1. Los menores tienen derecho a la protección y a los cuidados necesarios para su bienestar. Podrán expresar su opinión libremente. Ésta será tenida en cuenta en relación con los asuntos que les afecten, en función de su edad y de su madurez.

2. En todos los actos relativos a los menores llevados a cabo por autoridades públicas o instituciones privadas, el interés superior del menor constituirá una consideración primordial.

3. Todo menor tiene derecho a mantener de forma periódica relaciones personales y contactos directos con su padre y con su madre, salvo si son contrarios a sus intereses. 
de niños en la pornografía ${ }^{48}$ (en adelante el Protocolo Facultativo) y la ya mencionada Convención del Consejo de Europa para la Protección de los Niños contra la Explotación Sexual y el Abuso Sexual. El artículo 2 de la Directiva 2011/92 establece como pornografía infantil a:

cualquier material que represente de manera visual a un niño en una conducta sexualmente explícita real o simulada; cualquier representación de los órganos sexuales de un niño con fines primordialmente sexuales; cualquier material que represente de manera visual a una persona que parezca ser un niño en una conducta sexualmente explícita real o simulada o cualquier representación de los órganos sexuales de una persona que parezca ser un niño, con fines eminentemente sexuales; o imágenes realistas de un niño en una conducta sexualmente explícita o imágenes realistas de los órganos sexuales de un niño con fines primordialmente sexuales.

Siguiendo con las referencias explícitas al uso de medios telemáticos en esta forma de delito contra la integridad sexual de menores, la Directiva define al término "espectáculo pornográfico" como una "exhibición en directo dirigida al público, incluso por medio de las tecnologías de la información", buscando una mayor protección de las víctimas y la prevención más eficaz de este delito, habidas cuentas de que, como ya se ha dicho, son las llamadas nuevas tecnologías las que han potenciado el desarrollo de la pornografía infantil. ${ }^{49}$

El artículo 4 inciso 2 de la Directiva establece que en la Unión Europea las penas por "[h]acer que un menor participe en espectáculos pornográficos, captarlo para que lo haga, lucrarse por medio de tales espectáculos, o explotar de algún otro modo a un menor para esos fines" alcanzarán un máximo de al menos cinco años si el niño no ha alcanzado la edad de consentimiento sexual, y de al menos dos años si la alcanzado. El mismo artículo continúa en su inciso 3 diciendo que las penas máximas deberán ser de al menos 8 años si el menor no ha alcanzado la edad de consentimiento sexual, y de al menos cinco años si el menor ha alcanzado esa edad en los casos que se emplee coacción, fuerza o amenazas contra un niño que participe en espectáculos pornográficos, terminando, en su inciso 4 , con la imposición de penas privativas de libertad de una duración máxima de al menos dos años si el menor no ha alcanzado la edad de consentimiento sexual, y de al menos un año si el menor ha alcanzado esa edad, por asistir a sabiendas a espectáculos pornográficos en los que participen menores.

\footnotetext{
48 Aprobado mediante la Resolución de la Asamblea General de las Naciones Unidas A/RES/54/263 del 25 de mayo de 2000, en: "Protocolo facultativo de la Convención sobre los Derechos del Niño relativo a la venta de niños, la prostitución infantil y la utilización de niños en la pornografía" (2002) disponible en http://www.ohchr.org/SP/ProfessionalInterest/Pages/OPSCCRC.aspx (visitado 26 Jul 16).

${ }^{49}$ Por ejemplo, los reportes de casos de pornografía infantil en Internet en los Estados Unidos se han multiplicado por cinco desde el año 2010 al 2014 con una tendencia a un aumento aún mayor para el 2015: Carol Christian, "Child porn reports soaring with technology upgrades" (2015) disponible en http://www.chron.com/news/houston-texas/texas/article/Child-porn-reports-soaring-with-technology6105981.php (visitado 26 Jul 16).
} 
Siguiendo con la temática relacionada a este trabajo, la Directiva dice en su artículo 5 que "[1]a adquisición o la posesión de pornografía infantil se castigará con penas privativas de libertad de una duración máxima de al menos un año", 50 que "[e]l acceso a sabiendas a pornografía infantil por medio de las tecnologías de la información y la comunicación se castigará con penas privativas de libertad de una duración máxima de al menos un año", ${ }^{51}$ que "[1]a distribución, difusión o transmisión de pornografía infantil se castigará con penas privativas de libertad de una duración máxima de al menos dos años", ${ }^{52}$ que "[e]l ofrecimiento, suministro o puesta a disposición de pornografía infantil se castigará con penas privativas de libertad de una duración máxima de al menos dos años"53 y que "[1]a producción de pornografía infantil se castigará con penas privativas de libertad de una duración máxima de al menos tres años." 54

La legislación europea en cuestión deja a discreción de los Estados miembros la punibilidad de las conductas descriptas en los casos que la persona que parezca ser un menor resulte tener en realidad 18 años o más en el momento de obtenerse las imágenes y la utilización de los tipos establecidos en los incisos 2 a 6 del artículo 5 en los casos de que el productor de imágenes realistas de un menor participando en una conducta sexualmente explícita o imágenes realistas de los órganos sexuales de un menor, con fines principalmente sexuales, las tenga para uso privado, a no ser que para su producción se haya usado material que incluya a un niño real. Esto, sumado a que la constitución de estos delitos con la necesidad de dolo directo, tal como lo establece el inciso 1 del artículo 5, excluiría los casos en que las personas no tengan la intención de entrar en un sitio web con pornografía infantil o simplemente no saben de la existencia de este tipo de imágenes allí, parecería abrir la puerta para una defensa automática afirmando que no se sabe la edad de la víctima o que se entró accidentalmente un sitio web con dicho contenido, para evitar ser procesado por estos delitos. ${ }^{55}$ A los efectos de evitar esa posibilidad, la misma Directiva 2011/92 afirma que la repetición de la infracción y la presencia de pago para la obtención de acceso a materiales ilegales constituirían la prueba del carácter doloso de la conducta.

Finalmente, se establece que Estados Partes pueden proporcionar una defensa para las conductas descriptas cuando sean realizadas con propósitos médicos, científicos o similares. Además, también se permite a las autoridades públicas algunas de estas conductas para llevar a cabo procesos penales o para prevenir, detectar o investigar crímenes.

\footnotetext{
50 Directiva 2011/92 relativa a la lucha contra los abusos sexuales y la explotación sexual de los menores y la pornografía infantil y por la que se sustituye la Decisión marco 2004/68/JAI del Consejo, artículo5 Inciso 2.

${ }^{51} \mathrm{Ibid}$, inciso 3.

52 Ibid, inciso 4.

${ }^{53}$ Ibid, inciso 5.

${ }^{54}$ Ibid, inciso 6.

${ }^{55}$ Por ejemplo, en $R$ v Jayson [2003] 1 Cr App R 13, la Cámara de Apelaciones del Inglaterra declaró que "una persona no es culpable de un delito d" hacer "o" estar en posesión "de un pseudo-fotografía indecente contenida en un archivo adjunto de correo electrónico si antes de que abra el archivo adjunto no se da cuenta de que contiene o es probable que contenga una imagen indecente."
} 
Una cuestión contenciosa es la responsabilidad de los proveedores de servicios de Internet en los cuales se alojan los sitios con material de pornografía infantil o los usados para permitir su circulación. El artículo 25 de la Directiva establece medidas contra sitios web que contienen o transmiten dichos contenidos, lo que incluye el retiro de las páginas web con imágenes pornográficas de niños alojados en su territorio, así como fuera de sus fronteras, siempre que se incluya un procedimiento transparente y se ofrezcan garantías adecuadas, sobre todo con miras a garantizar que la restricción se limite a lo necesario y proporcionado, y que los usuarios estén informados del motivo de la restricción, incluyendo la posibilidad de revisión judicial.

Es necesario compatibilizar las medidas propuestas con los derechos humanos a la vida privada y la libertad de expresión, garantizados en los artículos 8 y 10 de la Convención Europea de Derecho Humanos, respectivamente y surgen cuestionamientos $^{56}$ acerca de si la tendencia a criminalizar ciertas actividades que tienen lugar en Internet no son formas de censura y el inicio de restricciones innecesarias a los derechos humanos mencionados, ${ }^{57}$ aunque el argumento que el derecho a la vida privada incluye la posesión y visualización de evidencia de un abuso sexual a un menor, lo que en definitiva es la pornografía infantil, es uno difícil de sostener.

\section{La pornografía infantil en el sistema segal argentino}

Argentina es signataria de la Convención sobre Derechos del Niño desde el 29 de junio de 1990 y la ratificó el 4 de diciembre del mismo año, siendo ésta luego incorporada con rango constitucional en forma explícita por el artículo 75 inciso 22 de la Constitución Nacional en su reforma del año 1994. De la misma manera, el 1 de abril del año 2002 firmó el Protocolo facultativo sobre la venta de niños, la prostitución infantil y la utilización de niños en la pornografía, el que fue aprobado por el Congreso Nacional mediante la Ley 25.763, ratificándolo el 25 de septiembre de 2003 y ha gestionado ser sido invitada para acceder al Convenio del Consejo Europea sobre Ciberdelitos. ${ }^{58}$

Hasta el año 2008, el citado artículo 128 del Código Penal, tipificaba la producción, publicación o distribución de imágenes pornográficas en que se exhibieren a menores de 18 años, resultado éste de la modificación impuesta por la Ley 25.087 de 1999 al original artículo 128 del Código Penal de la Nación de 1921. Con esta modificación, la conducta punible enfatizaba acciones que quedaron incluidas, pero no eran

\footnotetext{
${ }^{56}$ Por ejemplo, J Hornle, "Countering the dangers of online pornography - shrewd regulation of lewd content?" (2011) 2 European Journal of Law and Technology 1-26.

57 Para una análisis detallado a este respecto en el caso del derecho inglés, ver L Edwards, "Pornography, Censorship and the Internet", en L Edwards y C Waelde, Law and the Internet (compiladoras), 3ra edición, (Oxford: Hart Publishing, 2009).

${ }^{58}$ Existen diversos trabajos que refieren a que Argentina ha adherido al citado Convenio, pero esto no parece estar sustentado en la realidad. No existen en el Consejo de Europa a la fecha datos de la firma o pedido de ascensión por parte de Argentina, lo cual estaría corroborado por el Proyecto de Declaración presentado en la Cámara de Diputados de la Nación, bajo expediente 4027-D-2013, que solicita la adhesión al Convenio de Bruselas.
} 
suficientes, en la legislación argentina con la incorporación al derecho nacional del Protocolo facultativo sobre la venta de niños, la prostitución infantil y la utilización de niños en la pornografía. Además de no contemplar el fenómeno de la pornografía infantil en Internet, la Ley 25.087 tuvo algunas cuestiones de interpretación y desnudó las falencias de formación de los jueces en lo que a nuevas tecnologías se información se refiere. En el caso "M., E. s/recurso de casación", la Cámara de Casación revirtió el sobreseimiento dado a un médico que había enviado dos mensajes electrónicos con pornografía infantil a un foro de Internet, de los que usualmente son conocidos como newsgroups, entendiendo, correctamente, que el envío de un mensaje a tales foros constituía una forma de distribución. Pero lo que demostró ese caso fue la necesidad de una norma más inclusiva que pueda ser usada por jueces que, como los de la Cámara Nacional de Apelaciones en los Criminal y Correccional, desconocieran que de ninguna forma el envío de correos electrónicos a un newsgroup, cuya finalidad es distribuir información entre todos los miembros con un solo mensaje, puede ser interpretado como que no constituía "la realización del verbo típico", esto es, la distribución.

En el año 2008 el Congreso de la Nación sancionó la ley 26.388, que incorporó al Código Penal Argentino una serie de conductas típicas punibles relacionadas al uso de sistemas de información como medio de comisión de las mismas o como objeto de ellas, también conocida como la Ley de Delitos Informáticos. Esta Ley tipifica, entre otros, los siguientes delitos informáticos: violación, apoderamiento y desvío de comunicación electrónica, incluyéndolo en el art. 153, párrafo $1^{\circ}$ del Código Penal (en adelante $C P$ ); intercepción o captación de comunicaciones electrónicas o telecomunicaciones, como art. 153 , párrafo $2^{\circ} \mathrm{CP}$; acceso sin autorización a un sistema o dato informático, en el nuevo artículo 153 bis CP; publicación indebida de una comunicación electrónica, reformando el artículo $155 \mathrm{CP}$; acceso ilegítimo a un banco de datos personales, sustituyendo el artículo 157 bis, párrafo $1^{\circ} \mathrm{CP}$; revelación ilegítima de información registrada en un banco de datos personales, reformando el artículo 157 bis, párrafo $2^{\circ} \mathrm{CP}$; inserción de datos falsos en un archivo de datos personales, en el artículo 157 bis, párrafo $2^{\circ} \mathrm{CP}$, lo que anteriormente estaba regulado en el artículo 117 bis, párrafo $1^{\circ}$ e incorporado por la Ley de Protección de Datos Personales $\mathrm{N}^{\circ}$ 25.326; fraude informático, en el nuevo inciso 16 del artículo 173; daño o sabotaje informático, como artículos 183 y 184, incisos $5^{\circ}$ y $6^{\circ} \mathrm{CP}$; y, aunque en la Ley es la primera de las figuras incorporadas, por último tenemos la pornografía infantil por Internet u otros medios electrónicos, en el reformado art. $128 \mathrm{CP}$.

\section{El nuevo artículo 128 del Código Penal de la Nación reza:}

Será reprimido con prisión de seis (6) meses a cuatro (4) años el que produjere, financiare, ofreciere, comerciare, publicare, facilitare, divulgare o distribuyere, por cualquier medio, toda representación de un menor de dieciocho (18) años dedicado a actividades sexuales explícitas o toda representación de sus partes genitales con fines predominantemente sexuales, al igual que el que organizare espectáculos en vivo de representaciones sexuales explícitas en que participaren dichos menores. 
Será reprimido con prisión de cuatro (4) meses a dos (2) años el que tuviere en su poder representaciones de las descriptas en el párrafo anterior con fines inequívocos de distribución o comercialización.

Será reprimido con prisión de un (1) mes a tres (3) años el que facilitare el acceso a espectáculos pornográficos o suministrare material pornográfico a menores de catorce (14) años.

De esta forma se buscó adaptar la legislación, tanto a las obligaciones internacionales asumidas por Argentina, incorporadas al sistema legal argentino en una norma superior, como a las necesidades materiales resultantes del avance tecnológico y el cambio de hábitos de la sociedad.

La conducta establecida en el primer párrafo del artículo es similar a lo que el artículo 2 inciso c) del Protocolo facultativo sobre la venta de niños, la prostitución infantil y la utilización de niños en la pornografía describe como pornografía infantil, por lo que no parece correcta la interpretación que hace alguna parte de la doctrina que el artículo 128 no sigue al mencionado Protocolo y que el injusto típico sólo se perfecciona en la medida en que las representaciones de un niño dedicado a actividades sexuales explícitas o sus partes genitales sean reales, vale decir que la imagen representada corresponda "realmente' a un menor de dieciocho años [...] y no a imágenes simuladas o virtuales que no tienen existencia material." "Es "Esta interpretación no sólo no surge del texto del artículo, que no incluye la palabra "real" pudiendo hacerlo, sino que ignora que el proyecto original de la Ley se refería a imágenes y en su tratamiento en el Senado se modificó con la intención expresa de usar un concepto más amplio que incluyera todas formas de representación, no sólo imágenes. Aun si no existiera este antecedente del tratamiento del Senado y se tuviera que recurrir a reglas de interpretación que excluyan lo expresado por los legisladores durante el tratamiento de la norma, la palabra "representación", incluida intencionalmente en lugar de la de "imagen", es definida por el Diccionario de la Real Academia Española, en relación a este asunto $^{60}$, como, 1. Acción y efecto de representar; 2. Imagen o idea que sustituye a la realidad; y 4. Cosa que representa otra. "Representar", por su parte y también seleccionando lo relacionado con este tema, es definida por el mismo diccionario, como:

1. Hacer presente algo con palabras o figuras que la imaginación retiene; 2. Informar, declarar o referir; 4 . Recitar o ejecutar en público una obra dramática; 5. Interpretar un papel de una obra dramática; 6 . Sustituir a alguien o hacer sus veces, desempeñar su función o la de una entidad, empresa, etc.; 7. Ser imagen o símbolo de algo, o imitarlo perfectamente.

Esto es, algo que imite perfectamente a un menor real, que lo sustituya, también está alcanzado por el artículo 128 de Código Penal. Otra cosa es discutir si es conveniente,

\footnotetext{
${ }^{59}$ J Buompadre, Manual de Derecho Penal, parte especial (Buenos Aires: Astrea, 2012) en 230-231.

${ }^{60}$ Debido a que en ambos casos la tercera definición de las palabras que siguen no guarda relación con el tema en cuestión, la misma no ha sido incluida en la referencia.
} 
pero el artículo parece claramente seguir los preceptos del Protocolo Facultativo varias veces referido.

Con respecto a la conveniencia de tipificar como pornografía infantil las representaciones "virtuales" de menores de dieciocho años dedicados a actividades sexuales explícitas o toda representación de sus partes genitales confines predominantemente sexuales, esto no es algo que deba ser decidido siguiendo solamente análisis normativos y o de teorías penales, muchas de las cuales tienen gran contenido ideológico. Teniendo en claro que una imagen virtual de pornografía infantil que no representa a un niño real no causa un daño a un menor en particular, ${ }^{61}$ es necesario establecer mediante estudios multidisciplinarios la alegada propensión de quienes consumen este tipo de pornografía a luego o también consumir pornografía infantil "real", para ver si todo lo relacionado a la pornografía infantil virtual debe ser tipificado como un delito de peligro. Hasta tanto tales estudios no sean llevados a cabo, la decisión sobre el tema no deja de ser casi completamente ideológica, ya que el impacto que la pornografía infantil "virtual" tiene sobre la pornografía infantil "real" es, en el mejor de los casos, muy incierto.

La cuestión pasa por decidir si en el caso de duda se elige la opción de mayor protección a los menores, aun a costa de afectar conductas de adultos moralmente reprochables pero que pueden no causarles daño alguno, o la opción de privilegiar la libertad de adultos de llevar adelante acciones que pueden tener como resultado el daño de menores reales. De acuerdo a la postura prevaleciente a nivel regional, la respuesta parecería inclinarse indudablemente por la de minimizar la intervención penal y a la consiguiente no penalización de la conducta, pero, excediendo con creces el sentido y objetivo de este trabajo, sólo parece necesario aclarar que no es necesariamente cierto que tal intervención mínima sea requisito para la existencia de una sociedad más democrática ni que lo contrarío conlleve a la conformación de un estado autoritario. Ampliamente aceptada en la región, esta postura es de raíz puramente ideológica y se entiende por la experiencia relativamente reciente con estados realmente autoritarios que extendieron en forma indiscriminada la intervención penal. En lo que al tema que nos ocupa respecta, se puede observar que son justamente los países con mayor tradición democrática y con estados liberales consolidados los que han hecho efectiva la mayor intromisión del derecho penal en conductas relacionadas con la sexualidad de menores en casos en que el daño a los mismos es posible pero indeterminable.

En ese punto, es importante señalar que lo indeterminable es la existencia concreta o no del daño a los menores en el caso de permitir las conductas descriptas para pornografía infantil virtual pero de ninguna manera se propone que el tipo penal en si sea de alguna forma impreciso, ambiguo ni muchos menos. En el caso que se decidiera penalizar la pornografía infantil virtual, como parecería hace el art. 128 del Código Penal, esta tipificación debe ser llevada adelante en forma estricta e

\footnotetext{
${ }^{61}$ El bien jurídico protegido por este tipo de delitos es la "intangibilidad o indemnidad sexual de los menores de dieciocho años de edad, quienes precisamente en razón de su edad, no han alcanzado la madurez física, psíquica y sexual, motivo por el cual se los preserva de no ser sometidos a tratos sexuales anormales en sus modos", tal lo expresado en Delsavio, Jorge Armando s/recurso de casación" confirmado por la Corte Suprema de Justicia de la Nación, citado por H Fernandez Delpech, Manual de Derecho Informático (Buenos Aires: Abeledo Perrot, 2014) en 207.
} 
inequívoca, tal lo requerido por la Corte Interamericana de Derechos Humanos en, por ejemplo, Castillo Petruzzi y otros vs. Perú (Fondo, Reparaciones y Costas), 30/05/1999.

Otra cuestión importante que surge de la lectura del artículo 128 del CP es la de la edad de la víctima, ya que algunos doctrinarios sostienen que existe una incongruencia entre la edad de consentimiento para tener relaciones sexuales desde el punto de vista penal y la edad para ser víctima del delito de pornografía infantil. Más aun, autorizando el artículo 26 del nuevo Código Civil y Comercial de la Nación de Argentina que los adolescentes mayores de dieciséis años puedan consentir por ellos mismos a prácticas médicas invasivas, se podría alegar que desde esa misma edad podrían consentir a ser parte de lo que denominamos una representación pornográfica. Sin embargo, se puede aducir que nuevamente la respuesta se encuentra en recurrir por un lado a los dictados de los acuerdos internacionales de los que Argentina es parte, tal lo explicado anteriormente, y a los estudios que muestran el daño que se causa a un menor haya consentido originalmente o no, cuando las imágenes explícitas de su relación sexual son compartidas. ${ }^{62}$ Una solución que respete los acuerdos internacionales sería modificar los montos de las penas en los casos que las imágenes pornográficas sean de relaciones sexuales de menores con edad de consentimiento sexual y que hayan consentido a tales relaciones.

Quizás la cuestión más contenciosa es la de la tenencia de pornografía infantil, en la que el artículo 128 establece que será delito sólo cuando exista el dolo específico de distribución o comercialización. Los argumentos para la no penalización de la simple tenencia se centran en los derechos establecidos en el artículo 19 de la Constitución Nacional, en cuanto la tenencia de pornografía infantil se encontraría dentro de las acciones privadas, suponiendo quienes así lo afirman que tal conducta no ofende al orden ni la moral pública y no perjudica a un tercero. Esta postura es difícil de sostener, dejando de lado por supuesto y por las razones ya citadas el caso de la pornografía infantil virtual. El argumento no estaría completo sin hacer notar que en el fallo Rodriguez, Maria Belén c/ Google Inc. s/ dafios y perjuicios, CSJN Fallo R.522.XLIX la Corte Suprema de Justicia de la Nación afirmó que "[s]on manifiestas las ilicitudes respecto de contenidos dañosos, como pornografía infantil [...]. La naturaleza ilícita -civil o penal- de estos contenidos es palmaria y resulta directamente de consultar la página señalada en una comunicación fehaciente del damnificado o, según el caso, de cualquier persona, sin requerir ninguna otra valoración ni esclarecimiento", 63 esto es, repitiendo lo anteriormente expresado pero con el aval de la Corte Suprema de Justicia de la Nación, la pornografía infantil es inherentemente dañosa y de ilicitud manifiesta.

La pornografía infantil es un testimonio y una reproducción de un abuso sexual contra un menor o de un delito de corrupción de menores, y ante esto se podría aducir que el que simplemente tiene pornografía infantil no colabora con el daño ya causado a la integridad sexual del menor, que la simple tenencia no agrega nada a la situación del menor. Aquí se ha hecho un esfuerzo por ligar la tenencia de pornografía infantil a la tenencia de estupefacientes para consumo personal, lo cual parece a todas luces

\footnotetext{
${ }^{62}$ Ver notas 23 y 24.

${ }^{63}$ p. 16.
} 
erróneo. La tenencia de estupefacientes, un producto ilegal, para consumo personal no debe ser punida porque, tal como lo adujo la defensa en el caso Arriola, la intervención punitiva cuando no media un conflicto jurídico, entendido como la afectación a un bien jurídico total o parcialmente ajeno, individual o colectivo, no es legítima, siendo que en el caso de la pornografía infantil se afecta un bien jurídico ajeno. Todo esto dejando de lado que en el sistema normativo existen múltiples ejemplos en los que el Estado obliga a las personas a hacer algo para evitarse un daño a sí mismas, como es la obligación de usar cinturón de seguridad.

Por otra parte, el argumento de las acciones privadas en este caso conlleva una gran incongruencia con el ordenamiento penal como un todo, habiendo en el $C P$ un sinnúmero de delitos en los cuales la acción del sujeto activo no afecta de manera alguna a terceros y lo que se protege es algún bien jurídico vago e ideal como, por ejemplo, la seguridad pública. Resulta incongruente permitir que un individuo posea un material producto del abuso sexual a un menor que le ha causado un daño al mismo, como es la pornografía infantil, pero se le imponga una pena de seis meses a dos años si tiene un arma de fuego de uso civil sin la autorización correspondiente, artículo 189 bis del $C P$, siendo que en este caso el bien jurídico protegido es, como se dijo, un concepto vago y ambiguo, el daño es más que potencial y de consumarse se constituye en otros delitos. Si una persona tiene en su computadora miles de imágenes de pornografía infantil que no piensa distribuir ni comercializar no comete delito alguno, pero si tiene un arma de fuego que adquirió legalmente y por falta de uso e interés no renueva su cédula de legítimo usuario y la tiene guardada en un cajón con llave por años y lejos de cualquier potencial usuario, le corresponde la pena descripta. El mismo problema de congruencia se observa con el artículo 277 del Código Penal, que establece penas de prisión de seis meses a tres años el que,

"tras la comisión de un delito ejecutado por otro, en el que no hubiera participado: ${ }^{64}$ a) Ayudare a alguien a eludir las investigaciones de la autoridad o a sustraerse a la acción de ésta; b) Ocultare, alterare o hiciere desaparecer los rastros, pruebas o instrumentos del delito, o ayudare al autor o partícipe a ocultarlos, alterarlos o hacerlos desaparecer; c) Adquiriere, recibiere u ocultare dinero, cosas o efectos provenientes de un delito",

siendo nuevamente que, en estos casos el autor no agrega daño al ya causado. Se puede observar que, sobre todo en el inciso c) lo que se busca es desincentivar otros delitos al punir a aquellos que proporcionan un mercado para los bienes obtenidos durante los mismos. Ante esto es lícito preguntar cuan coherente y justo es penalizar a quien recibe un computadora que fue robada por otra persona sin su participación, pero no penarlo si en una computadora adquirida legalmente recibe miles de fotografías de pornografía infantil que registran explícitamente el abuso sexual de un menor de edad.

Es posible argumentar que la doctrina debería concentrar sus esfuerzos en definir con precisión qué es posesión, siendo que en lo informático la cuestión no es tan clara e

\footnotetext{
${ }^{64}$ Las negritas son propias.
} 
inequívoca como parece, en lugar de argumentar por los beneficios de difícil dilucidación de una decisión legislativa a todas luces desacertada.

\section{A modo de conclusión}

La pornografía infantil es una actividad que causa daño en los menores que toman parte en ella y hay un gran consenso internacional sobre que es una de las categorías de discurso, datos e información que no merecen la protección constitucional que se le brinda a otras formas de expresión. Sin embargo, en una sociedad informatizada con computación ubicua, la producción y distribución de pornografía infantil ha visto una expansión substancial.

La legislación internacional y la de otras jurisdicciones coinciden en penar las conductas relacionadas con la oferta de pornografía infantil, como son la producción, financiación, distribución, ofrecimiento, comercialización, publicación, facilitación o divulgación de la misma, tendiéndose en la mayoría de las jurisdicciones a penar también la posesión de pornografía infantil.

En el caso argentino el Congreso adaptó el Código Penal para tipificar como delitos ciertas conductas nocivas llevadas a cabo mediante, o que tenían como finalidad, sistemas informáticos. Dentro de estas conductas se incluyeron las relacionadas a la pornografía infantil y, de acuerdo a la redacción del artículo en cuestión, $128 \mathrm{CP}$, ésta incluiría la pornografía infantil virtual.

La penalización de la pornografía infantil virtual es un tema contencioso y se debería dejar sin efecto a la par de realizar estudios multidisciplinarios sobre el impacto que tiene ese tipo de pornografía infantil sobre la producción de pornografía infantil que usa menores reales, de la misma forma que, respetando los acuerdos internacionales, que además tienen jerarquía superior a las leyes en el sistema argentino, se debería estudiar la cuestión de la edad de la víctima para mantener la congruencia del sistema penal. Ante esto se propone una reducción de la pena cuando el menor de dieciocho años tiene edad para consentir relaciones sexuales.

En Argentina no está penalizada la simple tenencia de pornografía infantil, lo que consideramos tanto un desacierto como una falta de coherencia con otras figuras incluidas en el Código Penal, siendo el argumento del artículo 19 de la Constitución Nacional uno que pensamos no corresponde en este contexto.

Finalmente, se propone que el artículo 128 del Código Penal sea modificado de siguiente manera:

Será reprimido con prisión de seis (6) meses a cuatro (4) años el que produjere, financiare, ofreciere, comerciare, publicare, facilitare, divulgare o distribuyere, por cualquier medio, toda representación de una persona menor de dieciocho (18) años dedicado a actividades sexuales explícitas o toda representación de sus partes genitales con fines predominantemente sexuales, al igual que el que organizare espectáculos en vivo de representaciones sexuales explícitas en que participaren dichos menores. 
Será reprimido con prisión de cuatro (4) meses a dos (2) años el que tuviere en su poder, a sabiendas, en cualquier formato, representaciones de las descriptas en el primer párrafo.

Será reprimido con prisión de un (1) mes a tres (3) años el que facilitare el acceso a espectáculos pornográficos o suministrare material pornográfico a menores de catorce (14) años.

En los casos que el material descripto en el primer párrafo sea la representación la actividad sexual de un menor de dieciocho años con edad de consentimiento sexual que hubiere consentido a dicha actividad, la pena se reducirá en un tercio en todos los supuestos de los párrafos primero y segundo. 